\title{
A CONCESSÃO DO BENEFÍCIO DE PRESTAÇÃO CONTINUADA AO ESTRANGEIRO
}

\author{
Victor Celso Gimenes Franco Filho
}

Discente do Curso de Direito da Faculdade de Ciências Jurídicas, Contábeis e Administrativas de Presidente Prudente; Contato: vcg.victor@gmail.com

\section{RESUMO}

O presente estudo tem por objetivo tecer uma análise sucinta a respeito da possibilidade de concessão do benefício assistencial de prestação continuada ao estrangeiro (indivíduo não naturalizado). A questão se resume, a saber, se tal benefício é exclusivo de cidadãos brasileiros, ou se, do contrário, a ele fazem jus os estrangeiros residentes no país. Tal assunto é de interesse de toda sociedade e da comunidade internacional, já que geraria repercussão econômica que poderia afetar o erário, tendo em vista o grande número de benefícios que poderiam ser concedidos. Para tanto, faz-se necessário realizar a análise de concessão do benefício, seus requisitos e seu amparo legal.

Palavras-chave: Seguridade Social. Assistência aos desamparados. Benefício. Estrangeiros. Possibilidade.

\section{MÉTODOS}

Com o propósito de alcançar os objetivos de estudo traçados, o presente trabalho delimitase e centraliza-se seguindo os métodos dedutivo, histórico e comparativo, além de utilizar técnicas de pesquisa documental e bibliográfica.

\section{INTRODUÇÃO}

A Assistência Social ${ }^{1}$, uma das ramificações da Seguridade Social ${ }^{2}$, definida expressamente no "caput" do art. 203 da Constituição Federal', tem por objetivo garantir, independentemente de contribuição e a quem dela necessitar, a assistência aos desamparados. Pode-se afirmar ainda que, a assistência a estes desamparados esta prevista como um dos direitos sociais ${ }^{4}$, também chamados de direitos "novos" ou de segunda dimensão, elencados no art. 6o da Carta Magna 5 , os

\footnotetext{
${ }^{1}$ Segundo Fábio Zambitte Ibrahim, a assistência social pode assim ser classificada: "A assistência social tem o Estado na qualidade de gestorprovedor que promove a distribuição, mediante regras legais, de benefícios e serviços em favor dos hipossuficientes que habitam o país" (Curso de Direito Previdenciário. 17ạ ed., Rio de Janeiro: Impetus, 2012. p.9).

${ }^{2}$ Art. 194. "A seguridade social compreende um conjunto integrado de ações de iniciativa dos Poderes Públicos e da sociedade, destinadas a assegurar os direitos relativos à saúde, à previdência e à assistência social".

${ }^{3}$ Art. 203. "A assistência social será prestada a quem dela necessitar, independentemente de contribuição à seguridade social, e tem por objetivos: $[\ldots]^{\prime \prime}$.

${ }^{4}$ Conforme leciona o professor Nagib Slaibi Filho: "Mais importantes que os direitos liberais são os direitos "novos" ou direitos sociais, isto é, direitos públicos subjetivos à prestação de serviços públicos, como observa o sempre moderno Pontes de Miranda. [...] Os direitos sociais têm conteúdo positivo - direito individual à prestação de serviço público concreto e divisível. [...] O direito social visa assegurar o atendimento às necessidades diárias e permanentes e corresponde a um programa para fazer e conservar a igualdade entre os membros da sociedade política, nas expressivas palavras de Pontes de Miranda" (Direito Constitucional. 3a ed. Rio de Janeiro: Forense, 2009. p.306).

${ }^{5}$ Art. 60. "São direitos sociais a educação, a saúde, a alimentação, o trabalho, a moradia, o lazer, a segurança, a previdência social, a proteção à maternidade e à infância, a assistência aos desamparados, na forma desta Constituição".
} 
quais exigem uma ação positiva por parte do Estado, sendo função deste o dever de garanti-los integralmente por se tratarem de direitos fundamentais sociais.

$\mathrm{O}$ benefício de prestação continuada, previsto constitucionalmente no inciso $\mathrm{V}^{6}$ do mencionado art. 203, por sua vez, assegura as pessoas portadoras de deficiência e aos idosos, que comprovem efetivamente não possuir meios de prover à própria manutenção ou de tê-la promovida por sua família, a garantia de um salário mínimo mensal.

Outrossim, a Lei Orgânica da Assistência Social - Lei no 8.742/93 - regulamentou o inciso V do art. 203 da Constituição Federal e, através de seu art. 20 definiu as exigências para fazer jus ao benefício, quais sejam: "O benefício de prestação continuada é a garantia de 1 (um) salário mínimo mensal à pessoa portadora de deficiência ${ }^{7}$ e ao idoso com 70 (setenta) anos ${ }^{8}$ ou mais e que comprovem não possuir meios de prover a própria manutenção e nem de tê-la provida por sua família".

Além dos requisitos supracitados o $\$ 3^{\circ}$ do art. 20 da Lei no 8.742/93 prevê ainda como critério para a concessão do benefício a renda familiar mensal per capita inferior a $1 \frac{1}{4}$ do salário mínimo. Contudo, o Supremo Tribunal Federal declarou inconstitucional ${ }^{9}$ mencionado requisito, mantendo sua vigência tão somente até 31 de dezembro de 2014, para que no âmbito administrativo passe a ser validado.

\section{Beneficiários de acordo com a Lei Orgânica da Assistência Social (Lei no 8.742/93)}

Após a análise da previsão legal e dos requisitos para concessão do benefício de prestação continuada é primordial analisar-se quem são aqueles que podem ser considerados beneficiários de acordo com as normas legais.

O Decreto ${ }^{10} 1.744 / 95$, que regulamentava o benefício assistencial, assim previa: “Art. 4ㅇ․ São também beneficiários os idosos e as pessoas portadoras de deficiência estrangeiros naturalizados e domiciliados no Brasil, desde que não amparados pelo sistema previdenciário do país de origem". Contudo, o Decreto 6.214, de 26 de setembro de 2007 revogou o anterior e, a

\footnotetext{
${ }^{6}$ Art. 203. [...] "V- a garantia de um salário mínimo de benefício mensal à pessoa portadora de deficiência e ao idoso que comprovem não possuir meios de prover à própria manutenção ou de tê-la provida por sua família, conforme dispuser a lei".

${ }^{7}$ De acordo a Convenção sobre os Direitos das Pessoas com Deficiência e através da nova redação dada pelo Decreto no $7.617 / 2011$ a palavra "deficiência" é "um conceito em evolução, resultando na interação entre pessoas com deficiência e as barreiras atitudinais e ambientais que impedem sua plena e efetiva participação na sociedade em igualdade de oportunidades com as demais pessoas".

${ }^{8}$ Essa idade foi alterada pelo estatuto do idoso para 65 anos (artigo 34 c.c artigo 118 da Lei 10.741/2003).

${ }^{9}$ Em decisão dada na Reclamação 4.374, a Corte seguiu o entendimento já firmado pelo Plenário quando julgou inconstitucional o dispositivo ao analisar o Recurso Extraordinário 567.985, com repercussão geral.

${ }^{10}$ Decretos são instrumentos normativos editados pelo Poder Executivo para tornar efetivo o cumprimento da lei. Alexandre de Moraes, citando Esmein, "são eles prescrições práticas que têm por fim preparar a execução das leis, completando-as em seus detalhes, sem Ihes alterar, todavia, nem o texto, nem o espírito". (MORAES, Alexandre de. Direito Constitucional. São Paulo: Atlas, 2002, p. 427)
} 
partir de então, o Art. $70^{11}$ do Decreto 6.214/07 entendeu que o direito de ser beneficiário do BPC seria apenas do brasileiro naturalizado, domiciliado no país, desde que preenchidos os demais requisitos legais.

Por fim, o Decreto no 7.617, de 17 de novembro de 2011, alterou o dispositivo do art. 70 do Regulamento, adicionando a mencionado artigo nova redação: "Art. 7o. É devido o Benefício de Prestação Continuada ao brasileiro, naturalizado ${ }^{12}$ ou nato ${ }^{13}$, que comprove domicílio e residência no Brasil e atenda a todos os demais critérios estabelecidos neste Regulamento".

Sendo assim, a concessão do benefício para o brasileiro, nato ou naturalizado, é consolidada pela própria lei ${ }^{14}$. De outro modo, o debate jurídico gravita em torno do alcance deste benefício ao estrangeiro, indivíduo não naturalizado, já que este não foi incluído no rol taxativo dos beneficiários constantes na Lei 8.742/93 e do Regulamento do Benefício de Prestação Continuada, aprovado pelo Decreto no 6.214/07.

\section{Aspectos negativos à concessão do benefício ao estrangeiro}

Um dos principais argumentos utilizados para que o benefício de prestação continuada seja negado sumariamente ao estrangeiro é o fato de que, conforme preconiza o art. $10^{15}$ da Lei 8.742/93, a assistência social é um direito do "cidadão ${ }^{16 ”}$, considerando-se assim aqueles inscritos como eleitores. Sendo assim, o estrangeiro, que por proibição expressa do art. 14 , §20 ${ }^{17}$ da Constituição Federal, não possui direito ao voto, estaria excluído do rol de beneficiários.

Outro fato, considerado de maior relevância, é de que o estrangeiro acarretaria um ônus ao erário. O art. 195, §5으 da Constituição leciona: "nenhum benefício ou serviço da seguridade

\footnotetext{
11 “Art. 70. “O brasileiro naturalizado, domiciliado no Brasil, idoso ou com deficiência, observados os critérios estabelecidos neste Regulamento, que não perceba qualquer outro benefício no âmbito da Seguridade Social ou de outro regime, nacional ou estrangeiro, salvo o da assistência médica e no caso de recebimento de pensão especial de natureza indenizatória, observado o disposto no inciso VI do art. 4ํㅡ, é também beneficiário do Benefício de Prestação Continuada."

${ }^{12}$ Art. 12. "São brasileiros: [...] II - naturalizados: a) os que, na forma da lei, adquiram a nacionalidade brasileira, exigidas aos originários de países de língua portuguesa apenas residência por um ano ininterrupto e idoneidade moral; b) os estrangeiros de qualquer nacionalidade, residentes na República Federativa do Brasil há mais de quinze anos ininterruptos e sem condenação penal, desde que requeiram a nacionalidade brasileira". (Redação dada pela Emenda Constitucional de Revisão no 3, de 1994)

${ }^{13}$ Art. 12. "São brasileiros: I - natos: a) os nascidos na República Federativa do Brasil, ainda que de pais estrangeiros, desde que estes não estejam a serviço de seu país; b) os nascidos no estrangeiro, de pai brasileiro ou mãe brasileira, desde que qualquer deles esteja a serviço da República Federativa do Brasil; c) os nascidos no estrangeiro de pai brasileiro ou de mãe brasileira, desde que sejam registrados em repartição brasileira competente ou venham a residir na República Federativa do Brasil e optem, em qualquer tempo, depois de atingida a maioridade, pela nacionalidade brasileira"; (Redação dada pela Emenda Constitucional no 54, de 2007).

${ }^{14}$ Neste sentido José Afonso da Silva: “O princípio é o de que a lei não distingue entre nacionais e estrangeiros quanto à aquisição e ao gozo dos direitos civis (art. 3ํ, CC). Há, porém, limitações aos estrangeiros estabelecidas na Constituição, de sorte que podemos asseverar que eles só não gozam dos mesmos direitos assegurados aos brasileiros quando a própria Constituição autorize a distinção”. (SILVA, José Afonso da. Curso de Direito Constitucional Positivo. São Paulo: Malheiros, 2004, p. 337).

${ }^{15}$ Lei 8.742/93 - Art. 1․ "A assistência social, direito do cidadão [...]".

${ }^{16} \mathrm{O}$ professor Nagib Slaibi Filho assim define o sentido de cidadania: "No sentido estrito, cidadania refere-se ao poder jurídico de o indivíduo participar do governo, votando, sendo eleito, exercendo funções públicas, usufruindo serviços públicos e fiscalizando a atividade estatal. Este é o sentido referido no art. 5, LXXIII, da Constituição, ao se referir ao remédio jurídico processual da ação popular, legitimando para o seu exercício inicial o cidadão, isto é, aquele inscrito como eleitor" (Direito Constitucional. 3ạ ed. Rio de Janeiro: Forense, 2009. p.306).

${ }^{17}$ Art. 14. "A soberania popular será exercida pelo sufrágio universal e pelo voto direto e secreto, com valor igual para todos, e, nos termos da lei, mediante: [...] § 2‥ Não podem alistar-se como eleitores os estrangeiros e, durante o período do serviço militar obrigatório, os conscritos".
} 
social poderá ser criado, majorado ou estendido sem a correspondente fonte de custeio total", reforçando esta tese, entendendo ser necessária uma fonte para custear os gastos provenientes desta extensão do benefício aos estrangeiros.

Igualmente, os princípios da seletividade e da distributividade consagram um critério distintivo para a escolha das prestações previdenciárias disponibilizadas, e também para definição da clientela a ser atendida ${ }^{18}$.

A reserva do possível é tradução literal do princípio da seletividade e distributividade, garantia constitucional outorgada em prol do Estado no inciso III do parágrafo único do art. 194: "Parágrafo único. Compete ao Poder Público, nos termos da lei, organizar a seguridade social, com base nos princípios objetivos: [...] III - seletividade e distributividade na prestação dos benefícios e serviços [...]". Portanto, a seletividade e a distributividade tem status constitucional e outorgam legitimidade ao legislador para efetivar "escolha" sobre prestações e beneficiários a serem protegidos pelo Estado em determinado momento histórico ${ }^{19}$.

No âmbito dos tratados internacionais, o Instituto Nacional do Seguro Social defende a tese de que no âmbito da assistência social, não há tratados ainda firmados na esfera internacional. Deste modo, as despesas a serem custeadas com o pagamento de benefícios assistenciais a estrangeiros no território nacional ainda não encontram fonte de custeio subsidiada pelo país de origem necessitado. Enquanto não existente o indispensável tratado internacional, não haverá reciprocidade de direito em prol dos brasileiros residentes no exterior, nem participação no custeio ${ }^{20}$.

Argumenta-se ainda que, conforme o artigo 20, "item II" do Pacto Internacional de Direitos Econômicos, Sociais e Culturais (PIDESC) preceitua: “Os países em desenvolvimento, levando devidamente em consideração os direitos humanos e a situação econômica nacional, poderão determinar em que medida garantirão os direitos econômicos reconhecidos no presente Pacto àqueles que não sejam seus nacionais", e deste modo, o Brasil por ser um país em desenvolvimento, poderia determinar em que medida os benefícios alcançariam os estrangeiros.

Por fim, defende-se ainda o fato de que nenhum país do mundo teria tão grande generosidade ao ponto de conceder para seus imigrantes um benefício mensal. Qualquer país que adotasse tal política certamente seria invadido por imigrantes necessitados ${ }^{21}$.

\footnotetext{
${ }^{18}$ ROCHA, Daniel Machado da; BALTAZAR JUNIOR, José Paulo. Comentários a Lei de Benefícios da Previdência Social. 9ạ ed., Porto Alegre: Livraria do Advogado Editora, 2009. p. 37.

${ }^{19}$ ALENCAR, Hermes Arrais. Benefícios Previdenciários, 4ạ Edição, São Paulo, Leud, 2009, p. 580.

${ }^{20}$ ALENCAR, Hermes Arrais. Benefícios Previdenciários, 4ạ Edição, São Paulo, Leud, 2009, p. 579-580.

${ }^{21}$ O professor Hermes Arrais Alencar ressalta ainda que: “Existe a preocupação por parte da Administração Pública Federal de esse benefício, uma vez cabível a estrangeiros residentes no país, seja capaz de incentivar a vinda de nacionais dos países vizinhos na América do Sul ao Brasil, máxime 


\section{Aspectos positivos à concessão do benefício ao estrangeiro}

De acordo com o art. $3^{\circ}$, inciso IV, da Carta Maior: "Constituem objetivos fundamentais da República Federativa do Brasil [...] promover o bem de todos, sem preconceitos de origem, raça, sexo, cor, idade e quaisquer outras formas de discriminação". No que tange aos estrangeiros o art. 5ㅇ da mesma carta, ainda mais enfático, assim prevê: "Todos são iguais perante a lei, sem distinção de qualquer natureza, garantindo-se aos brasileiros e aos estrangeiros residentes no País a inviolabilidade do direito à vida, à liberdade, à igualdade, à segurança e à propriedade".

O artigo 194, inciso ${ }^{22}$, da Constituição, por sua vez, garante como principio da seguridade social a universalidade, que tem por desiderato tornar acessível a seguridade social a todas as pessoas residentes no país, inclusive estrangeiras.

Das normas internacionais, o Pacto de São José da Costa Rica (internalizado no Brasil pelo Decreto 678, de 06/11/1992), em seu art. 1ㅇ, “item i", dispõe que: “Os Estados-Partes nesta Convenção comprometem-se a respeitar os direitos e liberdades nela reconhecidos e a garantir seu livre e pleno exercício a toda pessoa que esteja sujeita a sua jurisdição, sem discriminação alguma por motivo de raça, cor, sexo idioma, religião, opiniões, políticas ou de qualquer outra natureza, origem nacional, ou social, posição econômica, nascimento ou qualquer outra condição social".

$\mathrm{O}$ art. 24 do mesmo Pacto garante ainda que: "Todas as pessoas são iguais perante a lei. Por conseguinte, tem direito, sem discriminação, a igual proteção da lei".

De acordo com o "caput" do art. 5으, da Constituição Federal, é assegurado ao estrangeiro, residente no país, o gozo de direitos e garantias individuais, em igualdade de condições com o nacional. Ademais, a assistência social é um direito fundamental, e qualquer distinção fere a universalidade deste direito ${ }^{23}$.

A condição do estrangeiro não o impede de usufruir os benefícios previstos pela seguridade social por ser assegurado ao estrangeiro ${ }^{24}$, residente no país, o gozo dos direitos e

\footnotetext{
diante da grande extensão de fronteira "seca" que o nosso território possui, capaz de facilitar a imigração" (Benefícios Previdenciários, 4⿳亠口冋 Edição, São Paulo, Leud, 2009, p. 579).

${ }^{22}$ Art. 194. "A seguridade social compreende um conjunto integrado de ações de iniciativa dos poderes públicos e da sociedade, destinadas a assegurar os direitos relativos à saúde, à previdência e à assistência social. Parágrafo único. Compete ao poder público, nos termos da lei, organizar a seguridade social, com base nos seguintes objetivos: I - universalidade da cobertura e do atendimento $[\ldots] "$.

${ }^{23}$ TRF 3a Região, Al nº 249149, Relatora Juíza Ana Pezarini, Órgão Julgador: 8aㅡ Turma, DJU: 21/2/2007 página: 123.

${ }^{24}$ Sergio Pinto Martins: "No nosso sistema, tem a Seguridade Social como postulado básico a universalidade, ou seja: todos os residentes no país farão jus a seus benefícios, não devendo existir distinções, principalmente entre segurados urbanos e rurais. Os estrangeiros residentes no país também devem ser contemplados com as disposições da Seguridade Social, e não só para aqueles que exercem atividade remunerada. A disposição constitucional visa, como deve se tratar de um sistema de seguridade social, a proporcionar benefícios a todos, independentemente de terem ou não contribuído" (Direito da Seguridade Social. São Paulo: Atlas, 2003, p. 77)
} 
garantias individuais, em igualdade de condições com o nacional em razão da máxima efetividade dos direitos fundamentais.

Quanto ao termo "cidadão" constante na lei 8.742/93, citado como empecilho para concessão do benefício, tem que se observar que tal expressão foi utilizada pelo legislador no seu sentido mais amplo ${ }^{25}$, já que o próprio Instituto Nacional do Seguro Social concede aos menores de idade e aos portadores de deficiências mentais, que, a rigor, não são cidadãos no sentido técnico do termo, o benefício de prestação continuada. No mais, em diversos momentos a própria lei utiliza o termo "pessoas", sendo certo ainda que a constituição quando criou o benefício utilizou o termo "a quem dela necessitar", não mencionando a palavra "cidadão" em nenhum momento.

A própria lei 8.742/93 é imperiosa ao igualar os direitos, sem discriminação de qualquer natureza: "Art. 4ㅇ. [...] IV - igualdade de direitos no acesso ao atendimento, sem discriminação de qualquer natureza".

Em relação ao PIDESC, este não pode ser invocado, pois de acordo com os princípios básicos na interpretação de tratados de direitos humanos: os tratados não podem ser invocados para piorar ainda mais a proteção institucional dos direitos. No mais, o próprio art. 5ㅇ, "item ii" assim estabelece: "não se admitirá qualquer restrição ou suspensão dos direitos humanos fundamentais reconhecidos ou vigentes em qualquer país em virtude de leis, convenções, regulamentos ou costumes, sob o pretexto de que o presente Pacto não os reconheça ou os reconheça em menor grau".

De outro modo, o Deputado Federal, Sr. Carlinhos de Almeida (PT-SP), no ano de 2011, propôs projeto de Lei para promover alterações no art. 20 da Lei 8.742/93, acrescentando a este o $\S \S 9$ e 10 , garantindo assim o direito do benefício ao estrangeiro, após preenchidos alguns requisitos peculiares.

De acordo com o projeto, o estrangeiro deverá comprovar residência ${ }^{26}$ no Brasil por no mínimo 4 (quatro) anos, sendo este período diminuído em certas hipóteses. De outro modo, exigir-se-ia que o estrangeiro seja registrado como permanente e possua residência contínua no território nacional, leia e escreva a língua portuguesa e contra este não exista condenação no

\footnotetext{
${ }^{25}$ Hermes Arrais Alencar: “Porém, em termos constitucionais, não encontra respaldo a discriminação pretendida pela Administração Pública Federal. Temos para nós que o termo "cidadão" utilizado no dispositivo não foi empregado no intuito de restrição, corrobora essa afirmativa o inciso IV do artigo 4을 da própria lei que editava os princípios da assistência social” (Benefícios Previdenciários, 4ạ Edição, São Paulo, Leud, 2009, p. 579).

${ }^{26}$ Paulo Gustavo Gonet Branco: “Direitos sociais, como o direito ao trabalho, tendem a ser também compreendidos como não inclusivos dos estrangeiros sem residência no País".
} 
Brasil ou no exterior por crime doloso a que seja cominada pena mínima de prisão abstratamente considerada superior a 1 (um) ano.

"Data vênia", o projeto satisfaz os anseios daqueles que lutam para que este direito tornese expresso em nossas normas infraconstitucionais. Porém, alguns aspectos são controversos, como o fato de exigir-se que o estrangeiro possua capacidade civil, já que segundo a lei brasileira, "os que, por enfermidade ou deficiência mental, não tiverem o necessário discernimento [...]", e os "menores de 16 (dezesseis) anos" são considerados absolutamente incapazes, gerando assim a exclusão de grande parte dos beneficiários que a lei enquadra como "portadores de deficiência".

De outro modo, na proposta do ilustre deputado, a utilização do filtro: "inexistência de denúncia, pronúncia [...]", poderia ferir diretamente o princípio da presunção de inocência, já que a Carta Magna assegura que "ninguém será considerado culpado até o trânsito em julgado de sentença penal condenatória" (art. $5^{\circ}$, LVII), ou seja, o acusado é inocente durante o desenvolvimento do processo e seu estado só se modifica por uma sentença final que o declare culpado $^{27}$.

Por fim, o Supremo Tribunal Federal reconheceu a repercussão geral ${ }^{28}$ do tema, porém, até o presente momento não há uma posição concreta da Corte, prevalecendo o entendimento majoritário da jurisprudência e da doutrina que em diversos casos já asseguram o direito de concessão do benefício de prestação continuada ao estrangeiro.

\section{CONCLUSÃO}

Os argumentos utilizados para que seja negado ao estrangeiro o deferimento do BPC são todos infraconstitucionais. Sendo assim, pela hierarquia das leis, o dispositivo constitucional é maior que todos os outros supracitados.

No entanto, faz-se necessário que o estrangeiro fixe residência por um período mínimo no Brasil para que lhe seja assegurado tal benefício, pois do contrário o país poderia ter de arcar com o ônus de pagar milhares de benefícios aos que migrassem para cá com este intuito.

Deve-se ainda levar em conta que os estrangeiros são pessoas que emigram culturas e religiões, tradições, hábitos e costumes de vida, trazendo consigo renda e benefícios aos que aqui habitam.

\footnotetext{
${ }^{27}$ MIRABETE, Julio Fabbrini. Processo Penal. 10ạ edição, revista e atualizada até setembro de 1999. São Paulo. Editora Atlas, 2000. p. 42.

28 "ASSISTÊNCIA SOCIAL - GARANTIA DE SALÁRIO MÍNIMO A MENOS AFORTUNADO - ESTRANGEIRO RESIDENTE NO PAÍS - DIREITO RECONHECIDO NA ORIGEM - Possui repercussão geral a controvérsia sobre a possibilidade de conceder a estrangeiros residentes no país o benefício assistencial previsto no artigo 203, inciso V, da Carta da República" (RE 587970/RG, Rel. Min. MARCO AURÉLIO, DJE. 01/10/2009).
} 
O benefício de prestação continuada, deste modo, deve ser estendido aos estrangeiros de maneira expressa, incluindo-se os mesmos no rol taxativo de beneficiários.

Deste modo, a Assistência Social é Direito Fundamental Social, devido a todos, sejam brasileiros ou estrangeiros aqui residentes, tornando-se meio para concretizar os mínimos existenciais e alcançar a dignidade da pessoa humana.

\section{REFERÊNCIAS}

ALENCAR, Hermes Arrais. Benefícios Previdenciários. 4ạ ed. rev. e atual., São Paulo: Liv. e Ed. Universitária de Direito, 2009.

BRANCO, Paulo Gustavo Gonet, MENDES, Gilmar Ferreira e COELHO, Inocêncio Martires. Curso de Direito Constitucional. 4a edição, São Paulo. Editora Saraiva. 2009.

BRASIL. Constituição (1988). Constituição da República Federativa do Brasil. Brasília, DF: Senado, 1988.

BRASIL. Decreto $\mathbf{6 . 2 1 4}$, de 26 de setembro de 2007. Regulamenta o benefício de prestação continuada da assistência social devido à pessoa com deficiência e ao idoso de que trata a Lei nº 8.742, de 7 de dezembro de 1993. Brasil: Imprensa Oficial, 2007.

BRASIL. Lei $\mathbf{8 . 7 4 2}$ de 07 de dezembro de 1993. Dispõe sobre a organização da Assistência Social e dá outras providências. Brasil: Imprensa Oficial, 1993.

IBRAHIM, Fábio Zambitte. Curso de Direito Previdenciário. 17ạ ed., Rio de Janeiro: Impetus, 2012. MARTINS, Sergio Pinto. Direito da Seguridade Social. São Paulo: Atlas, 2003.

MIRABETE, Julio Fabbrini. Processo Penal. 10a edição, revista e atualizada até setembro de 1999. São Paulo. Editora Atlas, 2000.

ROCHA, Daniel Machado da; BALTAZAR JUNIOR, José Paulo. Comentários a Lei de Benefícios da Previdência Social. 9ạ ed., Porto Alegre: Livraria do Advogado Editora, 2009.

SILVA, José Afonso da. Curso de Direito Constitucional Positivo. São Paulo: Malheiros, 2004. SLAIBI FILHO, Nagib. Direito Constitucional. 3a ed. Rio de Janeiro: Forense, 2009. 